\title{
KNOWLEDGE OF STUDENTS CONCERNING FOOTBALL GAME TECHNIQUE AND RULES
}

\author{
G. Dyakova ${ }^{1 *}$, T. Dyakov ${ }^{2}$ \\ ${ }^{1}$ Trakia University, Stara Zagora, Bulgaria \\ ${ }^{2}$ Chicago, USA
}

\begin{abstract}
Testing of 203, first and second year female students, of all specialties, at the Economic, Agrarian and Veterinarian-medical Faculties, with the Tracian University - Stara Zagora town, has been carried out, including 22 female students, educated in English language, on the specialty Veterinary Medicine. The purpose of this investigation is to establish the knowledge of female students regarding elements and rules of football game. Testing, Theoretical, Alternative, Graphic and Comparative analyses of percentage have been applied, for settlement of the research purpose set. We have conducted Testing of 12 questions, for collecting the quantitative information for establishment of the knowledge of female students, concerning football game elements and rules. Results and analysis show that female students lack serious knowledge concerning the football game technique and rules. The results got, give us a reason to deem that the including of female football in the educational programme, on Physical education and sport in the Higher School would have a serious educational effect and would fill in the shortage of knowledge with the female students, concerning the technique and rules of the most popular game in the world.
\end{abstract}

Key words: Higher school, Testing, Education

\section{INTRODUCTION}

Sport is acknowledged as a key factor of the development of young people, this conclusion has been drawn by the experts Djobova (1), Dochevska, Lazarov, Zdravkov, Ilieva and Djobova (2) in their investigation papers.

According to Doncheva (3), Dyakova (4), Yordanova (5), texts of the International chats concerning physical education and sort UNESCO (6), Chekoeva (7) and Petrov at all (8), Physical culture and sport training in the higher schools is possible to be realised successfully by applying the respective actions for perfection of already acquired in the previous levels of education, technical skills, psychological capabilities and tacticaltheoretical knowledge, specific and characteristic of the separate sports.

P. Tsonkova defends the idea that teaching and practical training on a sport should be in

*Correspondence to: Galina Dyakova,Trakia

University, Stara Zagora, Bulgaria, e-mail:

galinapdyakova@bitex.bg. GSM 0886846370 conformity with the interests and personal profile of the new generation students (9). The investigation of the motivation of students for studying connected with motor activity and sport, according to Petkov (10), Tsankova, Tsankov, Tsvetkova and Peltekova (11), Peltekova (12, 13), Mileva (14), Prokopov and Dimitrova (15) Kolev and Atanasova (16), contributes to an important analysis of the preferences of young people and increasing the effectiveness of teaching during the sport training.

According to Bozhkova (17), P. Angelova, Mollova and I. Angelova (18), Petkov and Angelova (19), Angelova (20), Petkov and Shoshev (21), Peltekova and Petkov (22), Physical education and sport contribute to the morpho-functional and psycho-physical perfection of students, to the development of physical qualities, motor skills and habits, improvement of the vital functions, aestheticizing of figure and decreasing the risk factors influence. 
Authors Denev (23, 24), Dikova, Averkiadu and Dimitrova (25) and Peeva $(26,27)$ define football as a sport being loved, with strongly expressed emotional character, simple rules and variety, and football study - developing skills, qualities and habits: discipline, responsibility, as well as important for the life realization, moral and volitional qualities for coping with the stress and increasing of emotional tone of the ones doing sport. According to Bozhkova, Ilieva, Stoilov and Bazelkov the team sports, football included, in the recent years increase their attractiveness and dynamics. They are popular and accessible, making them loved and played by persons of any age and sex, students included (28). Peeva indicates that innovations in the educational process on Physical culture and sport could be realized through introducing of new and non-traditional sports $(29,30)$.

Peltekova notes the advantages of the test form of assessment of the knowledge of the game rules (31).

Physical education and sport have educational function. Knowledge, increasing the efficiency of preparation is acquired in the educational process - Peltekova (32).

The purpose of the present investigation is establishing the knowledge of female students concerning football game elements and rules.

For achievement of the purpose, the following tasks have been set:

1. Theoretical survey of the problem.

2. Preparation of the test and conducting of the test.

3. Processing and analysing of the results got.

\section{METHODOLOGY}

Investigation has been conducted with 203, first and second year Bulgarian students from the Trakia University - Stara Zagora (TU) (Economic Faculty, Agrarian Faculty and Veterinarian-Medical Faculty, educated on the specialties "Agrarian Economy", "Regional Economy", "Business Economy", "Veterinarian Medicine", "Stock-breeding", "Agronomy", "Fish-breeding and Aquacultures", "Ecology and Environment protection", "Agrarian Engineering") and 22, first and second year foreign female students, educated in English language on the specialty Veterinarian Medicine. Due to the big difference in the numerical strength of the investigated target group of Bulgarian and foreign female students, educated in English language, we deem it not correct to make
DYAKOVA G., et al. comparison of the results between them. But in view of the fact that both types of groups work on one and the same programme, their investigation is necessary.

The following methods have been applied:

- Alternative analysis. We have calculated the percentage of the given reply compared to the total number of the tested persons.

- Testing - for collecting of quantitative information for establishing the knowledge of female students on football game elements and rules, we have performed a testing of 12 questions.

- Graphic analysis and

- Comparative analysis of percentages.

Investigation has been carried out in the summer semester of 2016/2017.

\section{RESULTS AND ANALYSIS}

The average age of the persons investigated was 19,8 years.

On Figure 1, it is presented the Graphic distribution of the percentages of Bulgarian female students, given correct and wrong answer to the test questions.

To the first test question (Figure 1) are presented four answers - a) with 2 half-times of 40 minutes each; b) with 2 half-times of 45 minutes; c) with 2 half-times of 50 minutes and d) no correct answer. The persons replied correctly that the duration of a football match is normally of 2 half-times of 45 minutes each (b), are only 3,88\% of the Bulgarian students. Very big percentage $-96,12 \%$ have given a wrong answer. By the second question we have aimed to check the knowledge regarding the break between the two half-times of a football match. Four answers have been offered: a) 10 minutes; b) 15 minutes; c) 20 minutes and c) no correct answer. The correct answer - b) 15 minutes has been given by $6,46 \%$.

Wrong answer has been given by $93,54 \%$. What is called the kick from the corner - only $7,76 \%$ of the investigated persons proved to know the correct answer - c) corner. The remaining 92,2\% have indicated one of the wrong replies - a) initial shot/kick; b) touch; d) penalty kick; e) offside or f) no correct answer. If any competitor is in off-side position, is not by itself a foul, is known by only $8,84 \%$ of the tested female students. The wrong answer has been indicated by $91,16 \%$. The procedure on the substitution of a player in a football match is allowed to be made when the game is stopped. 
DYAKOVA G., et al.

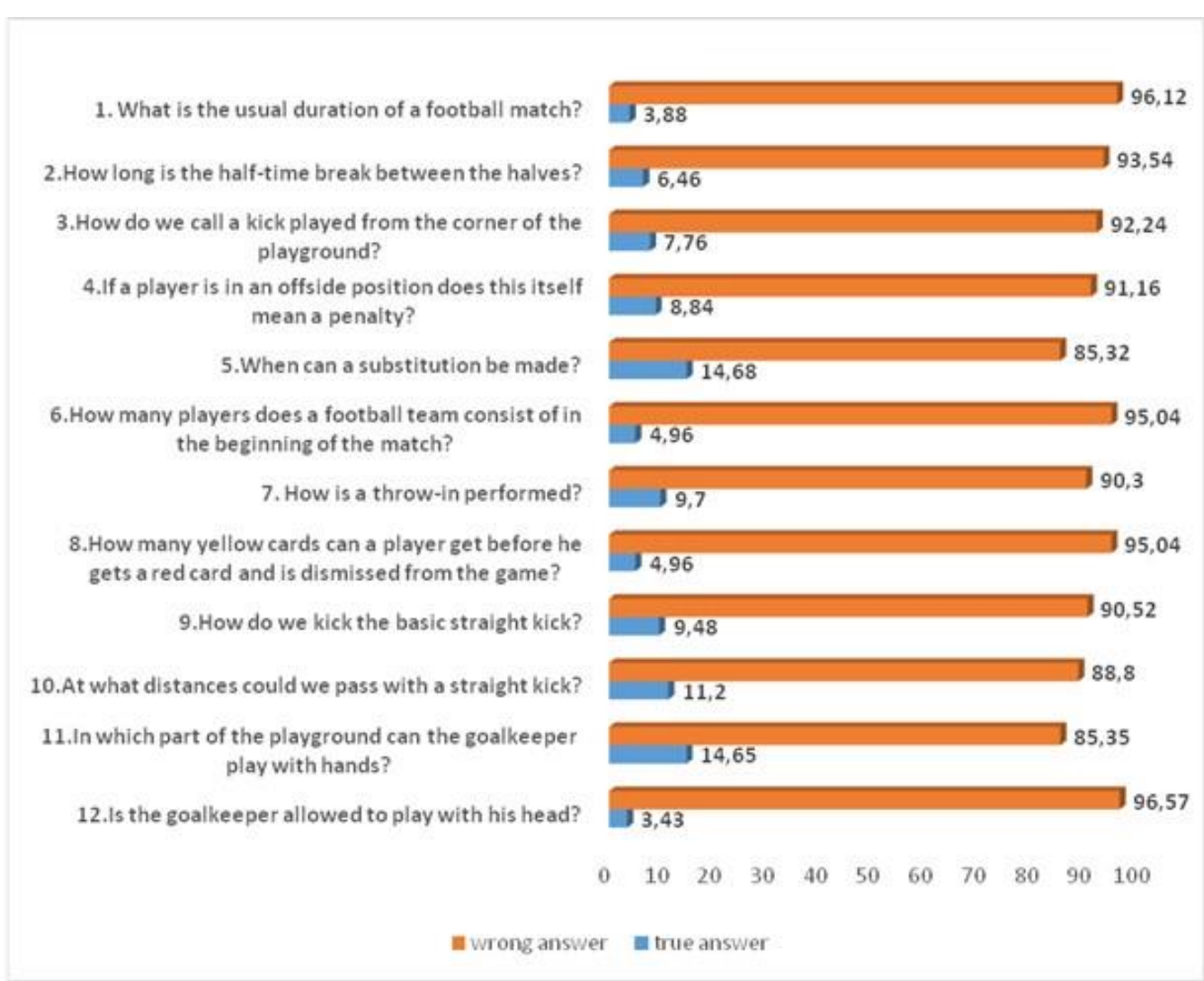

Figure 1. Percentages of Bulgarian female students, given correct and wrong answer to the test questions

In comparison with the answers to all questions, we could note that the highest percentage of the investigated persons, answered correctly is to the fifth question $14,68 \%$. The remaining $85,35 \%$ answered wrongly, by indicating the answer (a) during any time of the match; c) in the end of the halftime; e) after the execution of the initial shot or f) no correct answer. Insufficient knowledge with the female students is shown with the answers of the following question. Only 4,96\% know that football team is consisted of eleven players at the beginning of the match. Touch is executed by throwing the ball by two hands and a blow behind the head from the side line it is indicated by $9,7 \%$ of the female students, which is the correct answer. The remaining $90,3 \%$ gave wrong answer noting - b) by throwing the ball by two hands with a blow behind the head from the end line; c) through kick on the ball from the side line; d) through kick on the ball from the end line or e) no correct answer. One and the same player with two yellow cards in a football match gets a red one and that same player is not allowed to continue playing. It is the correct answer and it is indicated by only $4,96 \%$. The remaining 95,04\% have preferred one of the wrong answers: a) at one yellow card; c) at three yellow cards; d) at four yellow cards or no correct reply. By the ninth question, concerning the technique of football game, we have aimed to check the knowledge for execution of a Straight kick in football. From the four answers presented: a) by the top of the foot and kicking leg accompanying the ball; $b$ ) by the inner part of the foot and kicking leg accompanying the ball; c) by the outer part of the foot and kicking leg accompanying the ball and d) no correct answer, $9,48 \%$ of the investigated persons indicate the correct answer - a. The tenth question is connected with the ninth one, and requires defining the distances for execution of passes through a Straight kick. Most of those that could give a definition for the straight kick, with the previous question, answer correctly, and namely - at long distances $-11,2 \%$. To the question „In which part of the field the goal-keeper has the right to play by hands?", correct answer has been given by $14,65 \%$ of the female students. They know that it is the penalty area. Those who lack knowledge $-85,35 \%$, have indicated one of the incorrect answers: a) in the own area; c) in the whole field or d) no correct answer. The twelfth question proved to be difficult for the biggest part of the investigated quota $-96,57 \%$. They do not know that the goal-keeper has the right to play by a head. Few persons only $-3,43 \%$ have indicated the correct answer. 
DYAKOVA G., et al.

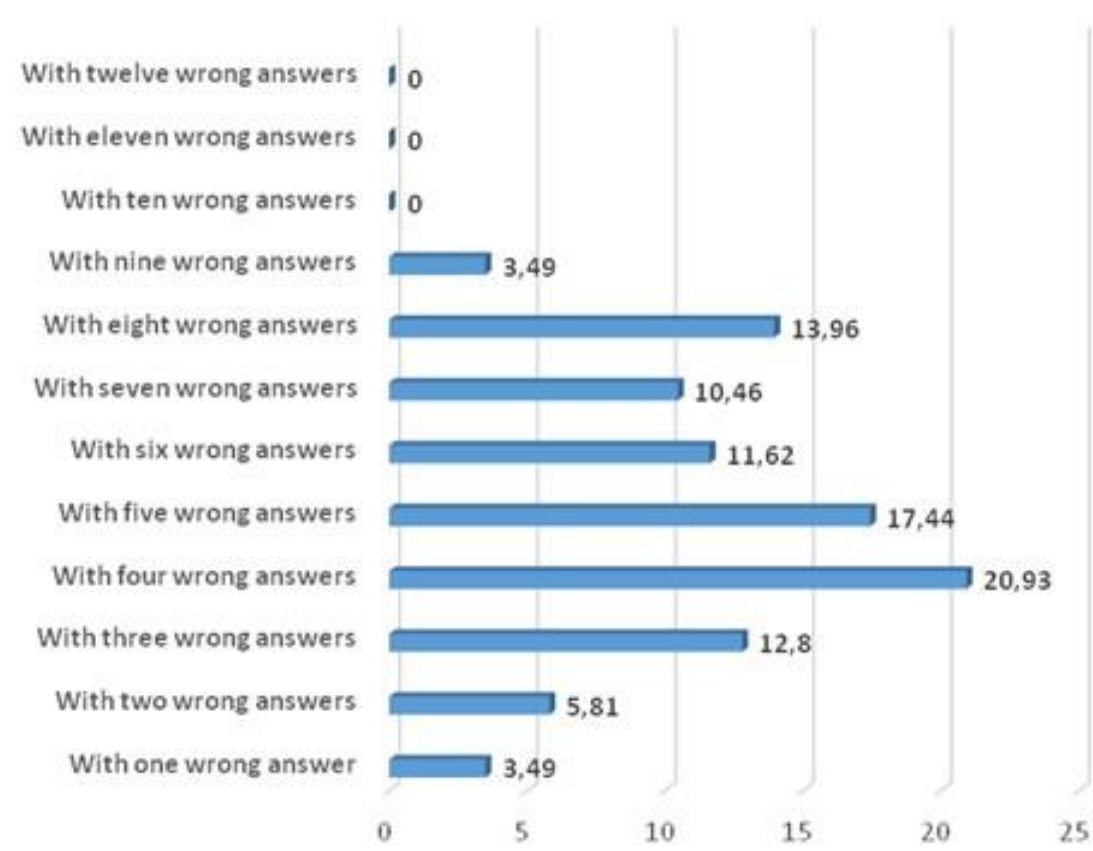

Figure 2. Number of wrong answers made by the Bulgarian female students (\%)

On Figure 2 we could see the condition of the knowledge of the Bulgarian female students on the technique and rules of football game. There is no one with absolutely correct test. Too small is the percentage with one $(3,49 \%)$ and two $(5,81 \%)$ wrong answers. But the percentage of female students with four wrong answers each is the biggest $-20,93$, followed by those with five $(17,44 \%)$ and eight $(13,96 \%)$ wrong answers.

On Figure 3 it is presented the graphic distribution of percentages of the Bulgarian female students, given correct and wrong answers to the test questions. We could see comparatively big percentages of female students given wrong answer.

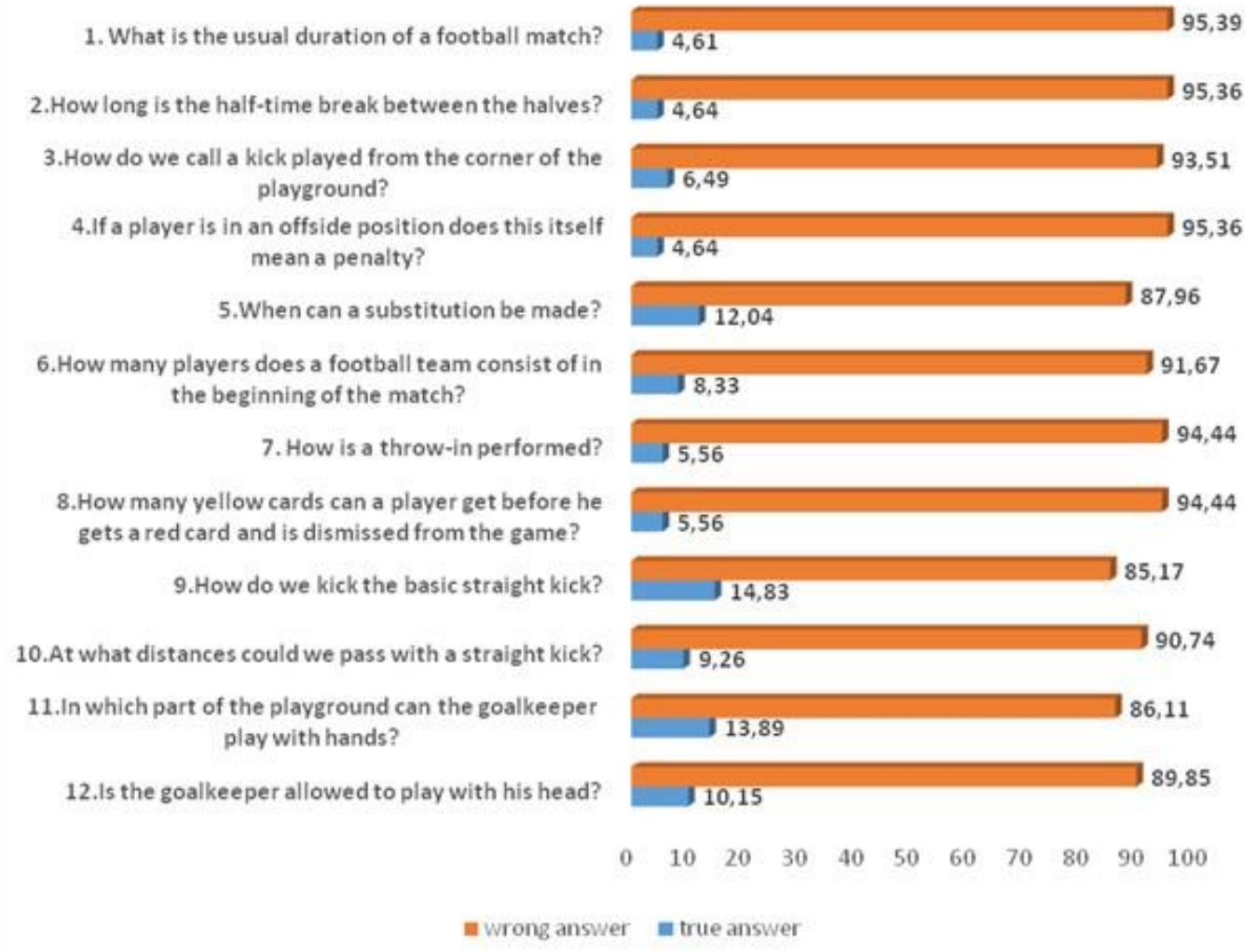

Figure 3. Percentage of foreign female students, given correct and wrong answer to the test questions 


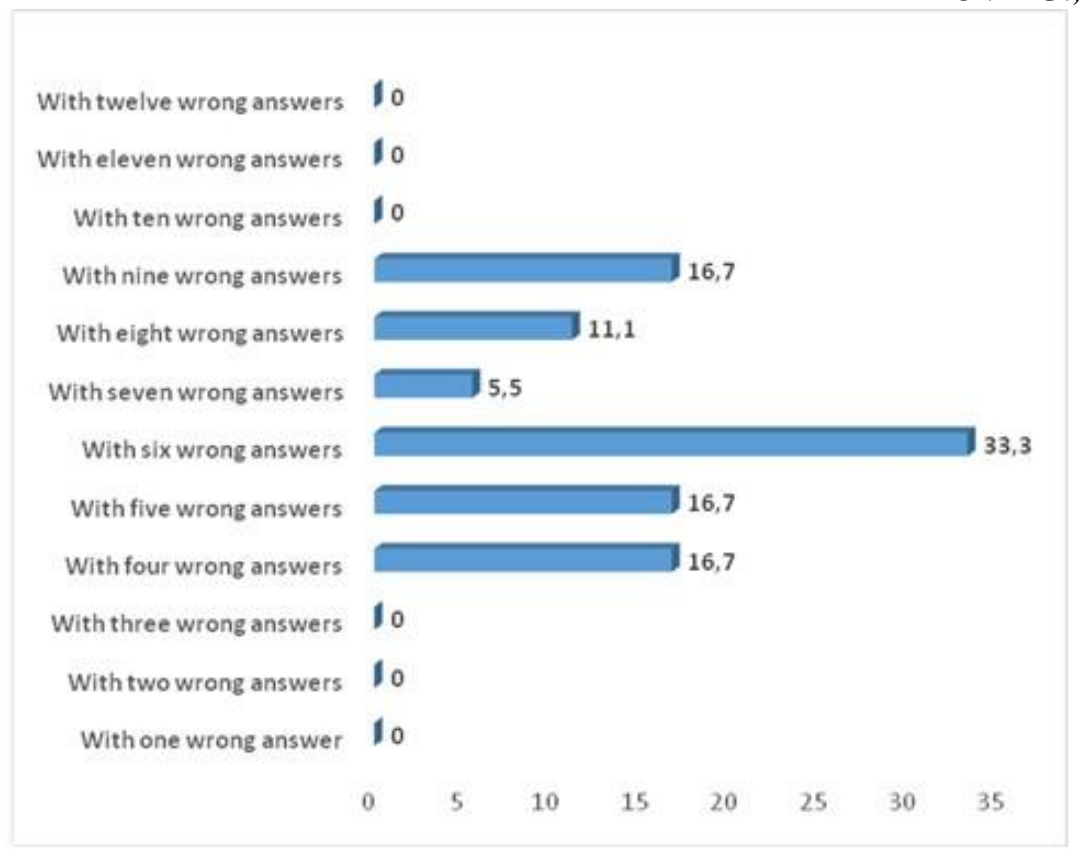

Figure 4. Number of wrong answers made by the foreign female students (\%)

From Figure 4 it is seen that with the biggest percentage $-33,3 \%$ are the female students made six wrong answers each, while those with four, five and nine wrong answers are with equal percentage $-16,7 \%$.

Results and analysis give us the ground to draw the definite conclusion, that female students lack serious knowledge on the football game technique and rules.

\section{Recommendations:}

The carried out investigation will have practical-application character with the inclusion of female football in the educational programme on Physical culture and sport in the higher school, which would contribute to serious educational effect and would fill in the deficiency of knowledge with the female students concerning the technique and rules of the most popular game in the world.

\section{REFERENCES}

1. Djobova, S., The Role of Sport in the Model of EU Youth Policy. Proceeding book of International Scientific Congress "Applied Sport Sciences", NSA Press, p. 440-442, 2017.

2. Dochevska, Y., Lazarov, I., Zdravkov, I.., Zankov, K., Ilieva. K., Martinova, D., Djobova, S., European week of sport editions 2015 \& 2016. Good practices manual, ISBN 978-619-90776-2-7, 2017.

3. Doncheva, M., Volleyball at a school on the threshold of the new millennium. Vol. 1, Varna, 2001.
4. Dyakova, G., Exploring the interests of students to various content in physical education. C \& H, cf. Pc. 1, S., 2005.

5. Yordanova, N., Analysis of the Educational Content of the Subject Physical Education and Sport.. C \& H, C., 2007.

6. International Charter for Physical Education and Sport (UNESCO). Legislative documents in the field of sport. Ministry of Youth and Sports. International charters and conventions in the field of sport. S., 2004.

7. Chekoeva, I.., Medical students' personal motivation for physical Activity during education. VI International Language Conference "Productive Language Skills for Academic Purposes", 7-8 October, Sb., 386-390, ISBN: 978-954-9685-64-0, Varna, 2011.

8. Petrov, L., Dimova, D., Eneva, P., Physical training in lessons of different character. International Scientific Congress "Sports, stress, adaptation", NSA, S., 1999.

9. Tsonkova, P., Positive example from the education of students sport teachers. Pedagogical almanac Technical University "St. Cyril and Methodius" 2018/c.2 p. 203207. ISSN: 2367-9360 (Online) ISSN: 1310-358X (Print)

10.Petkov, P., Motivation of the students from Trakia university for participation in physical education classes. Trakia Journal of Sciences, Volume 15, Supliment 1, ISSN 1313 - 3551, p. 433-442, 2017.

11.Tsankova, Zh., Tsankov, Ts., Tsvetkova, N., Peltekova, I., Investigations of relation of students to the basketball trainings in 
Higher schools. Col. Dept. "Psychology and Pedagogy”, „Personality, motivation, sport", vol. 10, ISBN 954-718-145-9, Publ. c/o Jusautor Sofia, C., p. 129-134, 2005.

12.Peltekova, I., "Sravnitelen analis program po fizuchesku vospitanie I sport $\mathrm{v}$ universiteta Bulgaria ang China" (in russian). Sb. Kompetencje współczesnego nauczyciela, Tamara Zacharuk, Aneta Niewęgłowska, ISBN 978-83-934036-9-1, Publ. Siedlce. Vol. 2, Polsha, p. 146-151, 2012.

13.Peltekova, I., Opit na student v Sofiyski uniwersitet zanimavashti se sport $\mathrm{w}$ perioda na obuchenie" (in russian), Material VI MNPK, Tula, ISBN 978-5-87954-644-6, Publ. TGPU, L.N. Tolstova, p. 380-383, 2011. RINC

14.Mileva, E., Interests of students from Teacher's faculty with National sport academy "Vasil Levski" to sport trainings. Sport and Science, extra issue c 3, p. 58-63, 2012.

15.Prokopov Iv., Dimitrova, N., Investigation of opinion of students ref trainings with sport during the free time. Tenth International Scientific Conference Contemporary Tendencies of Physical Education and Sport, University issue SU St. Kliment Ohridski, Sofia, ISSN 13142275, p. 319-323, 2018.

16.Kolev. Iv., Atanasova. K., Investigation of the wish and participation of students to cycling trainings, S and N, p.2 S, 2018.

17. Bozhkova, A., Modeling the preparation of educational-training process with studentsvolleyball players. Monograph Publ. Reporter EOOD. ISBN 987-954-8102-67-4, S. 128 p., 2008.

18. Angelova, P., Mollova, K., Angelova, Ivelina, STUDENT VIEW ON THE SIGNIFICANCE OF THE STRETCHING AND THE PRACTICAL APPLICATION Academic magazine "Management and education" International Conference EDUCATION, SCIENCE, ECONOMICS AND TECHNOLOGIES 28th - 29th June, 2018 BURGAS.

19.Petkov, P., Angelova, Petya, STUDY OF STUDENTS' PHYSIOMETRIC INDICATORS 57th Year conference of Russe University New industries, Digital Economy, Society - Projection of the future
DYAKOVA G., et al.

- Russe University "Angel Kanchev" Scientists Union - Russe, 2018.

20.Angelova, Petya, Therapeutic stretching with muscle-skeletal disfunction and lumbal pain. Publ., ISBN 978-954-305-4824, 2019.

21.Petkov, P., Shoshev, M., Study of female students resilience. Trakia Journal of Sciences,Volume 15, Supliment 1, ISSN 1313 - 3551, p. 442-446, 2017.

22.Peltekova, I., Petkov, Pl., Establishment of physical development level of female students from educational groups on physical culture and sport in Trakia University., Magazine „Science \& sport , b. 2 c, 2017, Year LXI, ISSN 1310-3393, p.161-168, 2017.

23.Denev, St., School football - varieties of education, Veliko Tarnovo, „I and B“, 109 p. ISBN: 978-619-7281-39-2, COBISS.BGID 1286837988 (monograph).

24.Denev, St., I teach football. Veliko Tarnovo: „I and B“, 2018, 103p. ISBN: 978-619-7281-36-1; $\quad$ COBISS.BG-ID 1286869988 (textbook)

25.Dikova, P., Averkuadu, P., Dimitrova, N., Essence and influence of games on the playing persons., Scientific conference of Dept. „Heavy athletics, box, fencing and sport for all” - "Challenges and perspectives before the sport science" „Problems before the contemporary sport”, C., p. 38, 2018.

26.Peeva, D., „Manuel on Physical culture in VTU „Todor Kableshkov”. Sofia, 2011.

27.Peeva, D., „Sport - a way of life of students from higher schools”. Mag. „, Sport and Science", Sofia, 2/ 2010.

28.Bozhkova A., Ilieva I., Stoilov I., Bazelkov St., Team sports in higher schools.. Sofia, Artgraph, ISBN 978-954-9401-83-7, 2014.

29.Peeva, D., „Innovations in the educational process on physical culture in HS by introducing of new and non-traditional sports". Sofia, monograph, 2010.

30.Peeva, D., „Manuel on physical culture in VTU „Todor Kableshkov”. Sofia, 2011.

31.Peltekova, I., Basketball knowing of rules, as a factor defining the efficiency of preparation of future sport teachers "., Annual of Sofia University „St. Kliment Ohridski”, Sport Dept. ISSN 0205-0692, Publ. „St. Kliment Ohridski”, vol. 85, S., p.185-197, 2013. 